NASA Technical Memorandum 105163 AIAA-91-1997

\title{
A Linear Control Design Structure to Maintain Loop Properties During Limit Operation in a Multi-Nozzle Turbofan Engine
}

Duane Mattern

Sverdrup Technology, Inc.

Lewis Research Center Group

Brook Park, Ohio

and

Peter Ouzts

National Aeronautics and Space Administration

Lewis Research Center

Cleveland, Ohio

Prepared for the

27th Joint Propulsion Conference

cosponsored by the AIAA, SAE, ASME, and ASEE

Sacramento, California, June 24-27, 1991 


\title{
A LINEAR CONTROL DESIGN STRUCTURE TO MAINTAIN LOOP PROPERTIES DURING LIMIT OPERATION IN A MULTI-NOZZLE TURBOFAN ENGINE
}

\author{
Duane Mattern ${ }^{\dagger}$ \\ Sverdrup Technology, Inc. \\ Lewis Research Center Group \\ Brook Park, Ohio 44142
}

\author{
Peter Ouzts ${ }^{\text {t+ }}$ \\ Advance Control Technology Branch \\ National Aeronautics and Space \\ Administration \\ Lewis Research Center \\ Cleveland, Ohio 44135
}

\begin{abstract}
$\underline{\text { Abstract }}$
The implementation of multi-variable control systems on turbofan engines requires the use of limit protection to maintain safe engine operation. Since a turbofan engine typically encounters limits during transient operation, the use of a limit protection scheme that modifies the feedback loop may void the desired "guarantees" associated with linear multi-variable control design methods, necessitating considerable simulation to validate the control with limit protection. An alternative control design structure is proposed that maintains the desired linear feedback properties when certain safety limits are encountered by moving the limit protection scheme outside of the feedback loop. This proposed structure is compared to a structure with a limit protection scheme that modifies the feedback loop properties. The two design structures are compared using both linear and nonlinear simulations. The evaluation emphasizes responses where the fan surge margin limit is encountered.
\end{abstract}

\footnotetext{
${ }^{\dagger}$ Controls Engineer, Member AIAA

${ }^{\dagger+}$ Aerospace Engineer
} 


\section{$\underline{\text { Nomenclature }}$}

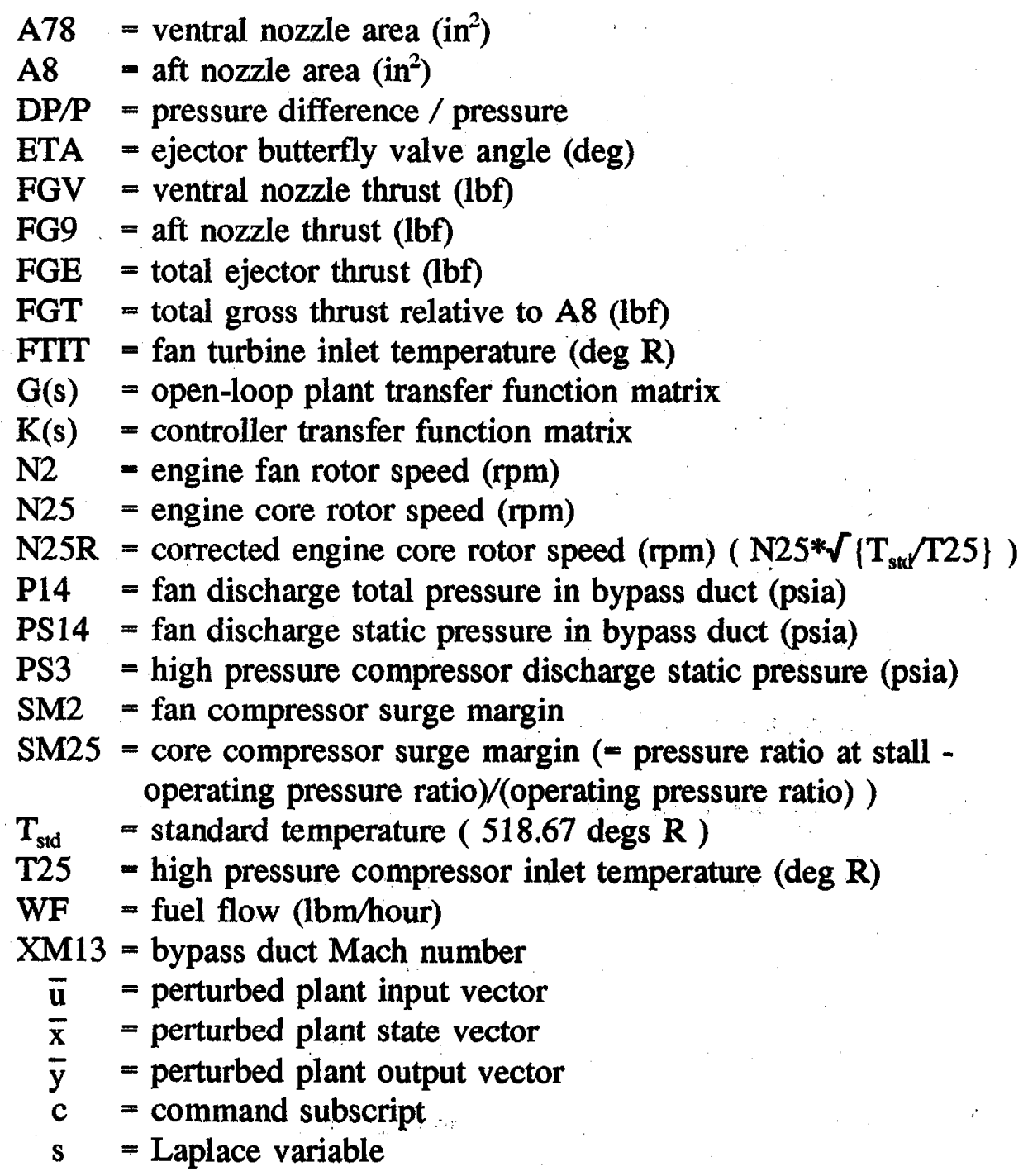


Introduction

Future Short Take-Off and Vertical Landing (STOVL) aircraft will require multiple sources of thrust to provide the forces and moments necessary to control the aircraft in low speed operation. A NASA Integrated Control Technology Program is investigating the problems associated with the integration of the airframe and propulsive control systems for STOVL aircraft. The integrated controls program at NASA Lewis Research Center is developing an Integrated Flight and Propulsion Control design methodology that includes the design of a "global" (airframe plus engine) linear controller as an intermediate design stage [1]. There has been some concern that a "global" linear controller may not perform as designed when the propulsion system is subjected to its operational limits. Limit operation has not typically been considered in published linear multi-variable control designs for jet engines [2-4]. Limits can be handled using nonlinear constrained optimization techniques [5], but these methods have their own set of associated problems and is not being discussed here. Since high-performance jet engines typically encounter limits during transient operation, the linear range of dynamic engine operation is small and the properties associated with linear multi-variable control designs may no longer be guaranteed. In this paper we address the possibility of using an alternative "control structure" for a turbofan engine that avoids changes in the feedback loop during limit operation. The term "control structure" is used to denote the variables selected to be controlled, which impacts the type of limit protection scheme that is used. The advantages of this alternative control structure are demonstrated on a multi-nozzle engine that is representative of a typical STOVL aircraft propulsion system.

In this paper, we first discuss the nonlinear limit operation of a typical turbofan engine. Next we describe the model of the turbofan engine used in this study and we introduce the 
control problems associated with the engine. Then we discuss two control system designs using different control structures; one design approach strives to achieve independent control of the three thrusts and the fan rotor speed, while the other approach controls the three thrust and a pressure ratio. For each of these two structures, a linear controller is designed and the resulting closed-loop linear systems are examined using time responses. Next, the two control structures are evaluated in a feedback loop that includes the linear controller, limit protection, and a nonlinear simulation of the plant. These two closed-loop nonlinear systems are compared using time responses. Finally, the results are discussed and summarized.

\section{Turbofan Nonlinearities}

In linear control system design, nonlinearities manifest themselves in three forms: variations in the linear system matrices $(A, B, C, \& D)$ that represent the plant, caused by changes in the nominal operating condition; "hard" physical actuator rate and range limits (slewing rates and saturation); and operational/safety limits imposed to extend the life of the plant. Typically it is assumed that the variations in the matrix elements of the linear model are slow relative to the plant dynamics. These matrix variations can be accommodated by gain scheduling [6] and feedback linearization [7], but these methods are not being considered here. We assume that the actuator rate and range limits have been accounted for within the linear design using linear actuator models that represent the "true" actuator bandwidth. Thus, our discussion centers on the nonlinearities due to the engine operational limits.

Typical operational limits for a turbofan engine are the fan and core compressor surge margins, the maximum fan and core rotor speeds, the maximum fan turbine inlet temperature (FTT), the maximum burner pressure, and the maximum and minimum combustion air/fuel ratio. 
Of these limited variables, only burner pressure, FTTT, and the rotor speeds are directly measurable. Currently, the FTIT measurement is not reliable enough to be used for control. The limits on the unmeasurable variables are reflected back onto the engine inputs resulting in input limit schedules that are a function of the engine outputs. Two such limits are the fuel flow acceleration/ deceleration (accel/decel) limit and the fan surge margin (DP/P) limit.

The accel/decel schedule is a set of variable bounds on the fuel flow as a function of $\mathrm{N} 25$, T25, and PS3. This limit schedule is determined a priori using an open loop nonlinear simulation of the engine. The schedule imposes a rate limit (in $\mathrm{rpms} / \mathrm{sec}$ ) on core rotor speed as a function of the minimum and maximum air/fuel ratio (lean and rich blowout), the maximum turbine temperature, and the compressor surge margin, as shown in Figure 1 [8]. The air/fuel ratio is a function of the inverse of WF/PS3, since PS3 is indicative of the combustor air mass flow rate. These limits are implemented as minimum and maximum bounds on the WF/PS3 ratio. An example limit schedule for the WF/PS3 ratio as a function of the corrected rotor speed, N25R, is shown in Figure 2 [9]. In Figure 2, the "droop line" is a line of constant thrust for fixed inlet conditions. On the droop line, the fan speed is decreasing as the operating point moves from lean to rich. The rotor speed schedule determines the "steady state line". A typical thrust response is shown in Figure 2, which shows how the WF/PS3 ratio increases to the acceleration limit at nearly constant corrected rotor speed. Then, as the rotor accelerates, the WF/PS3 ratio tracks the limit value until the desired thrust setting is reached. At that point, the WF/PS3 ratio decreases to the steady state scheduled value. Note that during the transient, when WF/PS3 is determined by the acceleration limit in Figure 2, the engine input, WF, is determined as a function of the plant outputs PS3, N25, and T25 (using the definition of N25R). The effect of this feedback is that there is a rate limit on the fuel flow when the fuel flow limit is encountered. 
Other limits, such as the maximum fan speed and the minimum burner pressure, also affect the fuel flow. WF is decreased if the maximum fan speed is exceeded and fuel flow is increased if the burner pressure falls below the minimum value.

The DP/P limit (fan surge margin) is another critical limit in turbofan engines. Figure $3[10]$ shows how the fan surge margin decreases during engine deceleration for an F100 engine with an appropriately scheduled nozzle area. During a gross thrust decrease on the F100 the surge margin decreases quickly as the fan pressure ratio increases. Then, with the surge margin limited, the much slower fan rotor speed follows along the surge limit line until the desired operating point is reached. The ability to maintain the fan surge margin greatly depends on the available control effectors. The control design on the GE16/J11A6 engine [11] uses a variable area bypass injector to control the exit area of the bypass duct, which adds a degree of freedom that is used to keep the fan surge margin within limits. The aft nozzle area is then used to obtain the desired thrust response. The surge margin cannot be directly measured, but it can be correlated with a function of the "delta $\mathrm{P}$ over $\mathrm{P}$ " pressure ratio (DP/P) $[10,12]$, which is defined as follows:

$$
\mathrm{DP} / \mathrm{P}=\frac{\mathrm{P} 14-\mathrm{PS} 14}{\mathrm{P} 14}
$$

Thus, it is possible to control the fan surge margin by controlling DP/P. The approach in reference [11] uses XM13, the fan tip discharge Mach number, as a controlled variable to maintain adequate fan surge margins. XM13 and DP/P are similarly related to SM2. The fan surge margin imposes a varying minimum total area limit schedule on the engine. In the following, the engine response due to the DP/P limit is considered. 


\section{Description of the Plant}

The engine model used in this study is representative of a multi-nozzle, mixed flow, vectored thrust engine envisioned for future STOVL aircraft applications. The engine is capable of generating four thrusts from the aft nozzle, the ventral nozzle, and from two wing-root mounted ejectors (see Figure 4 [13]). The mass flow for all the nozzles comes from the mixing region, where the core and bypass air streams merge into a mixed flow. The butterfly valve angles that determine the ejector areas are commanded identically, so no differential ejector thrust is used in this study. The simulation, described in reference [13], is a nonlinear component level model of the engine physics. A small perturbation linear model of the engine is generated at a design point representative of a STOVL aircraft approach to landing, with the propulsion system supporting approximately $60 \%$ of the weight of the aircraft with adequate distribution between ejector and ventral thrusts to provide the necessary pitch trim for the aircraft. The relatively slow temperature heat soaks and the faster volume dynamics are removed from the linear model, yielding a second order engine model with the two rotor speeds as the state variables. The resulting linear design model is of the form

$$
\dot{\bar{x}}=A \bar{x}+B \bar{u}, \quad \bar{y}=C \bar{x}+D \bar{u},
$$

where $\bar{x}, \overline{\mathrm{u}}$, and $\overline{\mathrm{y}}$ are the perturbed state, input, and output vectors as described below:

$$
\begin{gathered}
\overline{\mathrm{x}}=[\mathrm{N} 2, \mathrm{~N} 25]^{\mathrm{T}} \\
\overline{\mathrm{u}}=[\mathrm{WF}, \mathrm{A} 8, \mathrm{ETA}, \mathrm{A} 78]^{\mathrm{T}} \\
\overline{\mathrm{y}}=[\mathrm{N} 2, \mathrm{~N} 25, \mathrm{FG} 9, \mathrm{FGE}, \mathrm{FGV}, \mathrm{T} 25, \mathrm{PS} 3, \mathrm{SM} 2, \mathrm{DP} / \mathrm{P}]^{\mathrm{T}}
\end{gathered}
$$

The eigenvalues of the linear model are listed in Table 1. Four first order actuator models are used for WF, A8, ETA, and A78 in the design and evaluation process, with bandwidths of 10 , 
20,20 , and 20 radians/second, respectively. The fuel flow actuator time constant is conservative to compensate for the fuel transport delay. A nonlinear thrust estimator would normally have to be used to obtain the thrust outputs that is be fed back in the linear design, but it is omitted from both the design and the evaluation for simplicity as it does not add to the study of the limit operation problem. SM2 is provided for evaluation and is not used in the control designs.

\section{Control System Design}

A typical control objective for a multi-nozzle engine on a STOVL aircraft is to have independent control of the thrust from each nozzle. One way to achieve this using a linear multivariable control design method is to close the loop on the estimated thrust from each nozzle. Using this approach, a control design can be achieved for a small perturbation linear engine model. In the following we describe two linear control design structures using the $H_{\infty}$ control design technique. The details of the $H_{\infty}$ design method is not be discussed here, but there are sufficient references available $[14,15] . \quad H_{\infty}$ is not required, but it simplifies the incorporation of the specifications into the design.

The $H_{\infty}$ control design problem consists of finding the controller, $\mathrm{K}(\mathrm{s})$, which generates

control inputs, $\overline{\mathrm{u}}$, based on measurements, $\overline{\mathrm{y}}$, such that the plant, $\mathrm{G}(\mathrm{s})$, is stabilized and the infinity norm, $\|\cdot\|_{\infty}$, of the response of the controlled variables, $\bar{z}$, to exogenous inputs, $\vec{w}$, is

minimized. The three transfer functions that are of interest for this problem are the sensitivity function $S(s)$, the complementary sensitivity or transmission function, $T(s)$, and the control 
transmission function, $\mathrm{C}(\mathrm{s})$. It is desired to find a controller, $\mathrm{K}(\mathrm{s})$, which minimizes the following weighted norm:

$$
\min \left\|\begin{array}{l}
W_{S}(j w) \cdot S(j w) \\
W_{T}(j w) \cdot T(j w) \\
W_{c}(j w) \cdot C(j w)
\end{array}\right\|_{\infty} .
$$

The weighting functions $\mathrm{W}_{\mathrm{S}}, \mathrm{W}_{\mathrm{T}}$, and $\mathrm{W}_{\mathrm{C}}$ in the block diagram shown in Figure 5 are selected to meet the design specifications. The following control designs are formulated as command tracking problems.

\section{N2 Loop Design}

The first control design strives for independent control of the fan speed, $\mathrm{N} 2$, and the three thrusts, FG9, FGE, and FGV. $\mathrm{N} 2$ is included as an independent control variable, but $\mathrm{N}_{\mathrm{c}}$ is calculated as a function of the commanded total gross thrust, $\mathrm{FGT}_{\mathrm{c}}$, in the nonlinear evaluations. The four errors, eN2, eFG9, eFGE, and eFGV are fed back. The overall control implementation structure is shown in Figure 6. In Figure 6, three thrust commands from the airframe control system are used to generate a total gross thrust command, FGT . The FGT calculation is relative to the aft nozzle (i.e., the thrust that would be generated if all the mass flow from all the nozzles passed through the aft nozzle). FGT $_{c}$ is used to schedule a command value for the fan speed. Figure 6 also shows a block for limit protection logic that is used later in the paper for the nonlinear evaluation. The linear design specifications are as follows:

1) Closed loop bandwidths of $5 \mathrm{rads} / \mathrm{s}$ for $\mathrm{N} 2$ and $11 \mathrm{rads} / \mathrm{s}$ for the three thrusts. The thrust response specifications are relatively high for a turbofan engine, because it is possible to trade-off the flow from one nozzle to another without changing total gross thrust. The closed loop response of FGT is the same as the fan rotor response ( $5 \mathrm{rads} / \mathrm{s})$ and is 
limited by the accel/decel schedule.

2) Zero steady state error for step commands.

3) Decoupled responses between commanded channels.

4) Damped responses with no overshoot to step commands.

5) Avoid excess control rate and range actuation.

The nonlinear design specifications relative to the engine limits and the nominal operating point are as follows:

1) A DP/P limit protection scheme is imposed to maintain the desired fan surge margin. The nominal operating point being used for the design is close to the limit for DP/P.

2) The fuel flow accel/decel schedule is imposed indirectly using a rate limit on total gross thrust commands.

Figure 5 shows the $H_{\infty}$ framework that is used to design the first controller. The actuator models

weight the control rate in the $H_{\infty}$ control design. The sensitivity weights in Figure 5 are selected

to weight the low frequency error to provide the zero steady state error to step inputs and decoupled response, with a weight of one at a cross-over frequency corresponding to roughly 1.8 times the desired control bandwidth. The control weights are selected to reflect the rate and linear range limits of the actuators.

Open loop analysis of the engine model with the fuel flow accel/decel schedule installed revealed an effective fuel flow rate limit 35 times smaller than the capability of the fuel flow actuator for large perturbations to WF. The effective fuel flow rate limit is not used in the linear design because it reduces the small disturbance rejection properties of the controller. This effective fuel flow rate limit information is used to formulate a gross thrust rate limit, which is 
implemented outside of the feedback loop, thus maintaining the loop properties.

The resulting linear controller is 15 th-order. Reducing this controller using modal residualization of the fast modes results in a 4th-order controller. A comparison of the full and reduced order controller's singular values compare well up to 20 radians $/ \mathrm{sec}$ and the design meets all of the stated linear design criteria. The controller eigenvalues are listed in Table 1. Note that the four eigenvalues represent the four loop integrals which effectively make this controller a multivariable proportional plus integral, "PI", controller.

Figure 7 compares the linear controller response to a FG9. step input of $600 \mathrm{lbf}$, with and without the fan speed schedule implemented to show that the controller is capable of meeting the desired thrust response while maintaining the $\mathrm{N} 2$ schedule. Step commands are not typical for thrust commands, as the thrust command is filtered by the airframe controller in an integrated control design, but they are being used here to compare the linear controllers. The top plot in Figure 7 shows the aft nozzle gross thrust response, which is the same with and without the N2 schedule. Note in the fifth plot that DP/P has decreased beyond the perturbation limit value for this operating point of -0.0034 . Figure 7 also shows a $5 \%$ decrease in fan surge margin for this linear controller without limit protection, which is unacceptable. Thus, DP/P limit protection is required.

\section{DP/P Loop Design}

This control design strives for independent control of DP/P, and the three thrusts, FG9, FGE, and FGV. The steady state value for N2 is determined indirectly, since FG9, FGE, and FGV determine FGT, and FGT and DP/P establish N2. The feedback variables are eDP/P, eFG9, eFGE, and eFGV. Figure 8 shows the overall control implementation structure. In Figure 8, the 
three thrust commands from the airframe are used to generate a $\mathrm{FGT}_{\mathrm{c}}$ which is used to calculate a scheduled value for $\mathrm{DP} / \mathrm{P}_{\mathrm{c}}$.

If a steady state optimal criterion is used to design the fan speed schedule (specific fuel consumption, for example), then a DP/P schedule that is generated using the trim values for D.P/P at steady state operating points determined by the N2 schedule will satisfy the same optimal criterion in steady state. Additionally, since DP/P is now part of the feedback loop, the limit protection for fan surge margin has become part of the linear control design. This reduces the amount of time it takes to check out the controller, since a separate DP/P limit protection scheme does not have to be separately designed and validated.

The control design specifications are the same as before with DP/P replacing N2, with the exception that the bandwidth for DP/P is the same as the bandwidth of the three thrusts, (11 radians/second). The same actuator models as those used in the N2 loop design are used for the DP/P loop design. Figure 5 shows the $H_{\infty}$ framework that is used for the design with the errors now including eDP/P instead of eN2. The resulting controller is 15 th-order. Reducing this controller using modal residualization of the fastest modes results in a 6th-order controller. 'The full and reduced order controller singular values compare well up to 20 radians $/ \mathrm{sec}$. An attempt was made to reduce the controller to 4 th-order to match the order of the $\mathrm{N} 2$ loop design, but this resulted in increased coupling between thrusts, particularly an oscillation between FGE and FGV. Further investigation revealed a complex pair of poles in the 6th-order controller that provided high frequency decoupling of the thrusts. The relationship between this complex pole pair and the thrust coupling is currently being investigated. The eigenvalues of this controller are listed in Table 1. Note that the first four eigenvalues represent the four loop integral terms. The 
controller design meets all the linear design specifications. Figure 9 compares the DP/P loop design responses to a $600 \mathrm{lbf}$ step in FG9 ${ }_{c}$ with and without the DP/P $\mathrm{P}_{\mathrm{c}}$ schedule. Note that the DP/P schedule does not change very much, but it does change enough to match the fan speed schedule in steady state.

Both linear controllers meet the linear design specifications. A problems arises with the N2 loop design only when the DP/P limit specification is considered. In order to investigate this further, we compare the controller responses with a DP/P limit protection scheme included with the N2 loop design. Admittedly, that the following nonlinear responses for the N2 loop design are highly dependent on the DP/P limit protection logic, but that is the point. A separate limit protection design needs to be completed and checked out before this N2 loop design is acceptable. The DP/P loop design has the DP/P limit protection while still satisfying the steady state $\mathrm{N} 2$ schedule. There may be a problem with the DP/P loop design in terms of maintaining rated engine thrust over time with a worn engine. This question has not yet been addressed.

\section{Comparison of Controllers with DP/P Limit Protection}

Figure 6 shows the control implementation structure with the limit protection logic for the accel/decel schedule and the fan surge margin installed for the N2 loop design. This structure with a nonlinear model of the plant is used to evaluate the two control structures. Admittedly, both the DP/P loop design and the N2 loop design suffer from the same problem when the accel/decel schedule is encountered. An inelegant solution for the following simulation is to provide a thrust command that will not encounter the accel schedule. A $600 \mathrm{lbf}$ FG9 step is passed through a first order filter of 3 radians/sec to generate a first order FG9 command. This is equivalent to converting the accel/decel schedule to a thrust rate limit, which is conservative 
and not a realistic solution, but it is used here to investigate the DP/P limit responses.

During the course of this investigation it was discovered that it is unreasonable to analyze the responses of a multivariable control system with limit protection when a limit is encountered without including integral windup protection for the linear control. The reason for this is that in most multivariable controllers the control outputs are a function of all of the control states and the control state derivatives are a function of all of the controller inputs. That is to say that the controller is not decoupled. Thus, if any of the controller outputs are modified due to some limit criteria (increasing all the areas to meet the DP/P limit, for example), all of the controller integrals have to be modified for windup protection, since each integral contributes to the controller output. Therefore, in the following, a simple, multivariable integral windup protection scheme is implemented on the $\mathrm{N} 2$ loop design. The resulting $\mathrm{N} 2$ loop design responses are thus dependent on this limit protection and integral windup protection scheme. The point is that this design for fan surge margin protection does not have to be performed for the DP/P loop design.

Figure 10 compares the N2 loop design with DP/P limit protection to the DP/P loop design for the first order filtered $600 \mathrm{lbf}$ FG9 $9_{\mathrm{c}}$ input. The following items should be noted in Figure 10:

1) The FG9 thrust responses for both loops are very close.

2) The $\mathrm{N} 2$ tracking for the $\mathrm{N} 2$ loop design is upset slightly by the limit protection. The steady state values for $\mathrm{N} 2$ in both responses are the same.

3) The DP/P limit protection scheme for the N2 loop design causes coupling and oscillation of FGE and FGV that is undesirable. A refinement of the limit protection scheme nnay alleviate this coupling.

4) The DP/P schedule commands a slight increase in DP/P which enables the DP/P loop 
design to match the fan speed schedule.

An alternative limit protection and multivariable integral windup protection schemes may provide improved closed loop DP/P limit responses for the N2 loop design and this is currently being investigated. The limit protection and multivariable windup protection for the accel/decel schedule are still required for both designs. Techniques for addressing this limit are also being considered.

\section{$\underline{\text { Summary }}$}

An alternative control structure was investigated to avoid the nonlinear analysis associated with the DP/P limit due to fan surge margin. Several different points were brought up and are summarized below.

1) Open loop analysis of the plant plus known limit protection schemes should be performed. In the example discussed, the accel/decel schedule was included into the open loop model and revealed an effective fuel flow rate limit for large fuel flow perturbations that was 35 times slower than the capability of the physical fuel flow actuator. This "effective" fuel flow rate limit was used to provide a gross thrust rate limit outside of the feedback loop that was used in the analysis of the DP/P limit protection scheme.

2) Closed loop fan speed control in the N2 loop design was replaced by DP/P closed loop control in the DP/P loop design. A DP/P schedule was generated from the trim values of DP/P corresponding to the operating points defined by the N2 schedule. The transient response of N2 in the DP/P loop design was well behaved (first order) and the steady state values for $\mathrm{N} 2$ matched the scheduled value without closed loop control of $\mathrm{N} 2$.

3) The closed loop control of DP/P in the DP/P loop design made the fan surge limit 
protection scheme part of the linear controller design. This yiellded predictable DP/P limit operation with the linear control and reduced the amount of time required necessary to evaluate the DP/P loop design. The N2 loop design required an additional limit protection design step to accommodate the fan surge margin limit.

\section{$\underline{\text { Acknowledgement }}$}

The authors would like to thank Dr. Sanjay Garg for his assistance in formulating the engine control design problem in the $H_{\infty}$ control design framework. 


\section{$\underline{\text { References }}$}

1 Garg S., Ouzts P.J., Lorenzo C.F., Mattern D.L., "IMPAC - an Integrated Methodology for Propulsion and Airframe Control", 1991 American Controls Conference.

2) Sain M.K., Peczkowski J.L., Melsa J.L., Alternative for Linear Multivariable Control with Turbofan Engine Theme Problem, National Engineering Consortium, Inc., Chicago, 1978.

3) Garg S., "Turbofan Engine Control System Design Using the LQG/LTR Methodology", NASA CR 182303, June 1989.

4) Athans M., Kapasouris P., Kappos E., Spang H., "Linear-Quadratic Gaussian with LoopTransfer Recovery Methodology for the F-100 Engine", Journal of Guidance, Nav., \& Control, Vol.9, No.1, Jan.-Feb., 1986, p.45.

5) Stimler, D.M., "Scheduling Turbofan Engine Control Set Points by Semi-Infinite Optimization", Automatica, Vol. 25, No. 3, pp 413, 1989.

6) Shamma, J.S., Athans, M., "Analysis of Gain Scheduled Control for Nonlinear Plants", IEEE Transactions on Automatic Control, Vol. 35, No. 8, August 1990, p 898-907.

7) Phillips S., Mattern D., "Feedback Linearization for Control of Air Breathing Engines", AIAA-91-2000, presented at the 27th Joint Propulsion Conference, 1991.

8) Sobey A.J., Suggs A.M., Control of Aircraft and Missile Powerplants, John Wiley and Sons, Inc., New York, N.Y., 1963, p 185.

9) Arpasi D.J., Cwynar D.S., Wallhagen R.E., "Sea-Level Evaluation of Digitally Implemented Turbojet Engine Control Functions", NASA TN D-6936, Sept., 1972.

10) "F100 Multivariable Control Synthesis Program, Volume 1 - Development of F100 Control System", Systems Control, Inc., AFAPL-TR-77-35, June, 1977.

11) Polley J.A., Adibhatla S., Hoffman P.J., "Multivariable Turbofan Engine Control for Full Flight Envelope Operation", ASME 88-GT-6, presented at the Gas Turbine and Aeroengine Congress, June, 1988.

12) Beattie,E.C., "Control Mode Studies for Advanced Variable-Geometry Turbine Engines", Air Force Aero-Propulsion Laboratory, AFAPL-TR-75-7, Nov. 1974, p 13-15. 
13) Drummond C.K., Ouzts P.J., "Real-Time Simulation of an F110/STOVL Turbofan Engine", NASA TM 102409, Oct., 1989.

14) Reichert R.T., "Application of $H_{\infty}$ Control to Missile Autopilot Design", AIAA Paper 893550, Proceedings of the AIAA Guidance, Navigation and Control Conference, Boston, MA, August 1989, pp. 1065-1072.

15) Garg S., Mattern D.L., Bright M.M., and Ouzts P.J., "H-Infinity Based Integrated Flight/Propulsion Control Design for a STOVL Aircraft in Transition Flight," AIAA Paper 90-3335, Guidance, Navigation and Control Conference, Portland, OR, August 1990.

Table I Eigenvalues for the Linear Plant and controllers

\begin{tabular}{|l|c|c|}
\hline Plant & N2 Loop Design & DP/P LoOp Design \\
\hline-2.97 & -0.008 & -0.02 \\
-6.33 & -0.02 & -0.02 \\
& -0.02 & -0.02 \\
& -0.02 & -0.02 \\
& & $-12.56+/-1.65 i$ \\
\hline
\end{tabular}




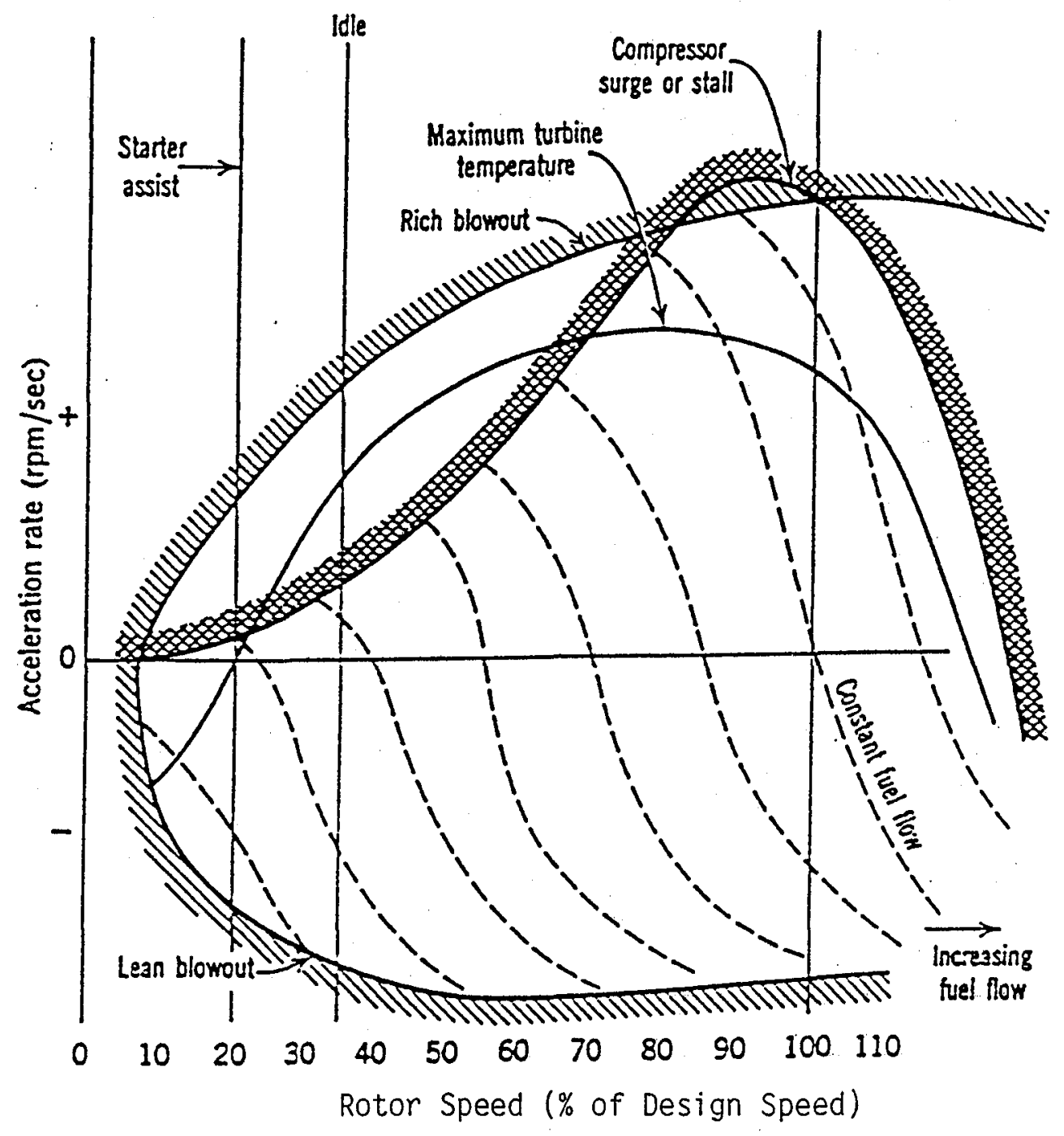

Figure 1 Typical Turbojet Acceleration Limits [8] 


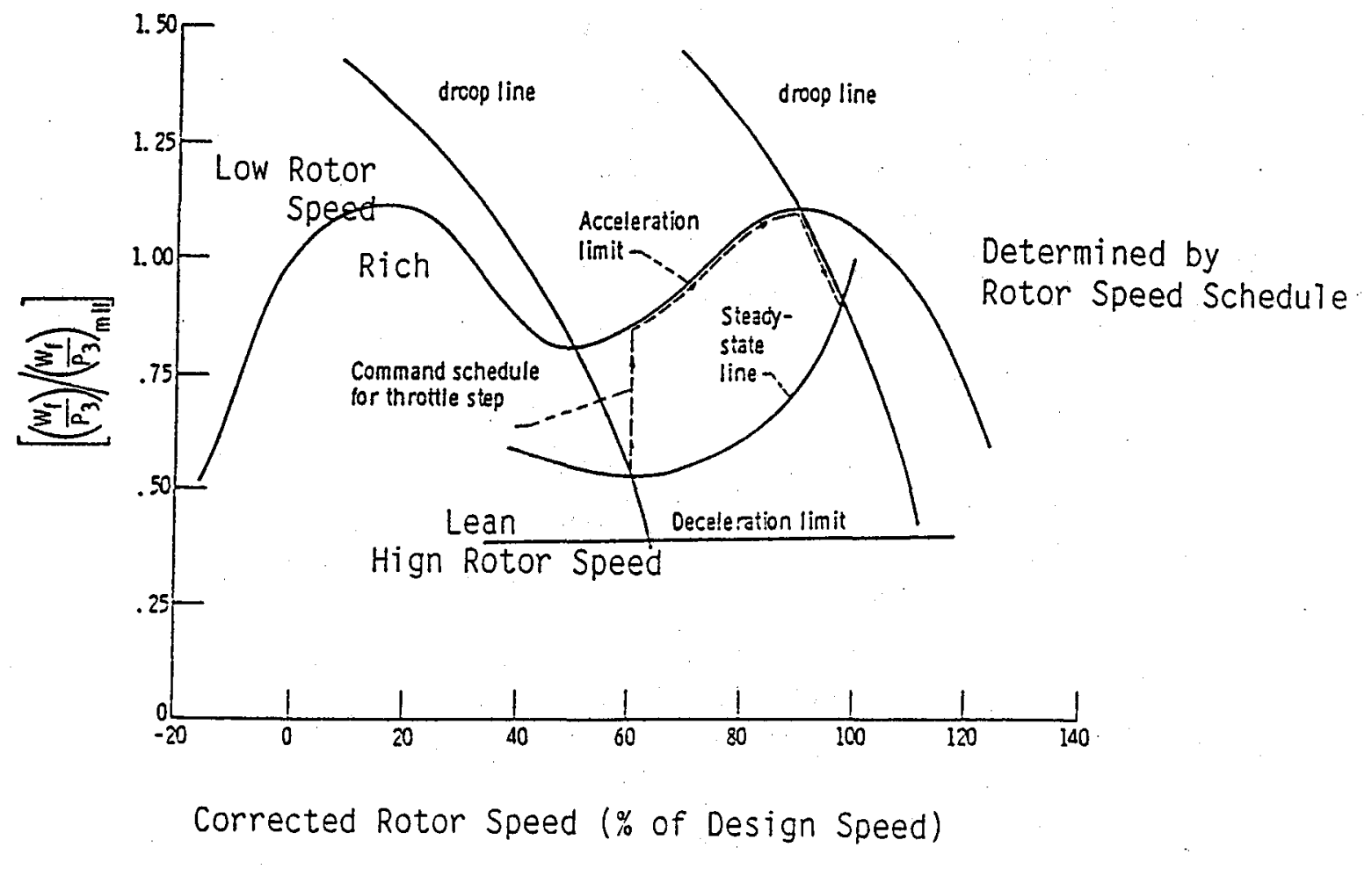

Figure 2 Typical Engine Fuel Control Operating Map Showing Acceleration and Deceleration Limits [9]

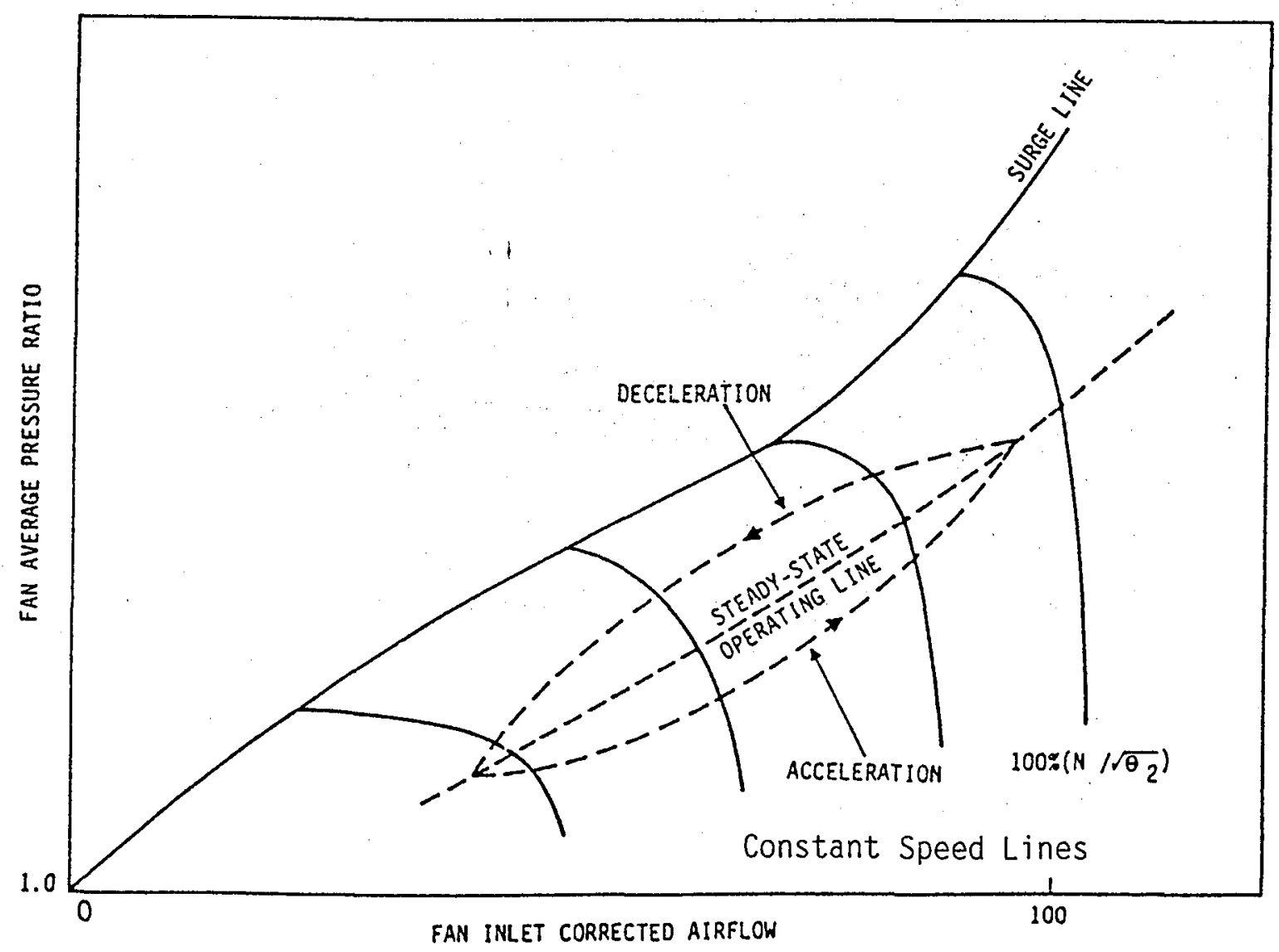

Figure 3 Fan Surge Margin Change During Transient (F100 engine with scheduled nozzle area)[10] 


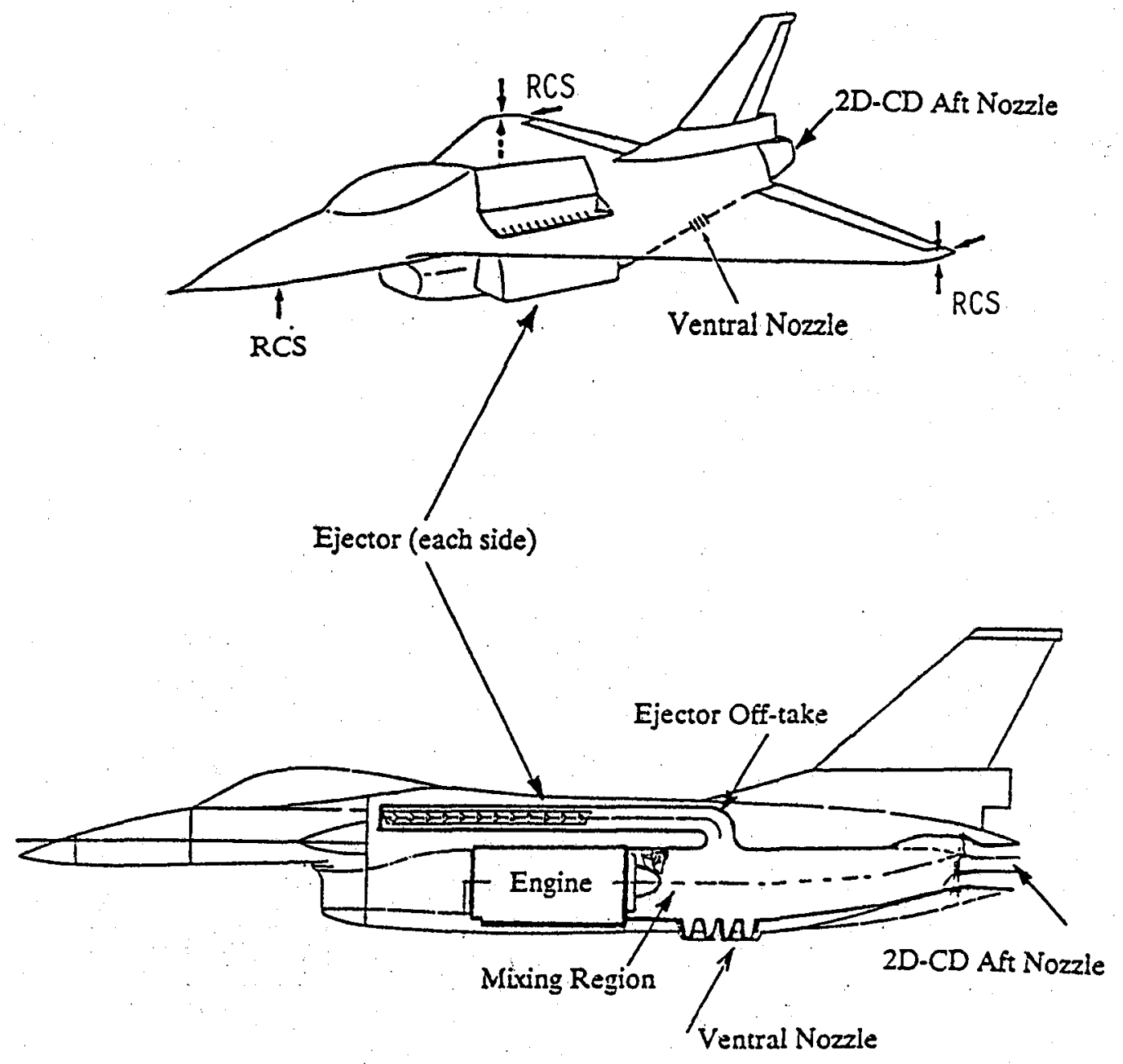

Figure 4 STOVL Aircraft Configured with Ejectors [13] 


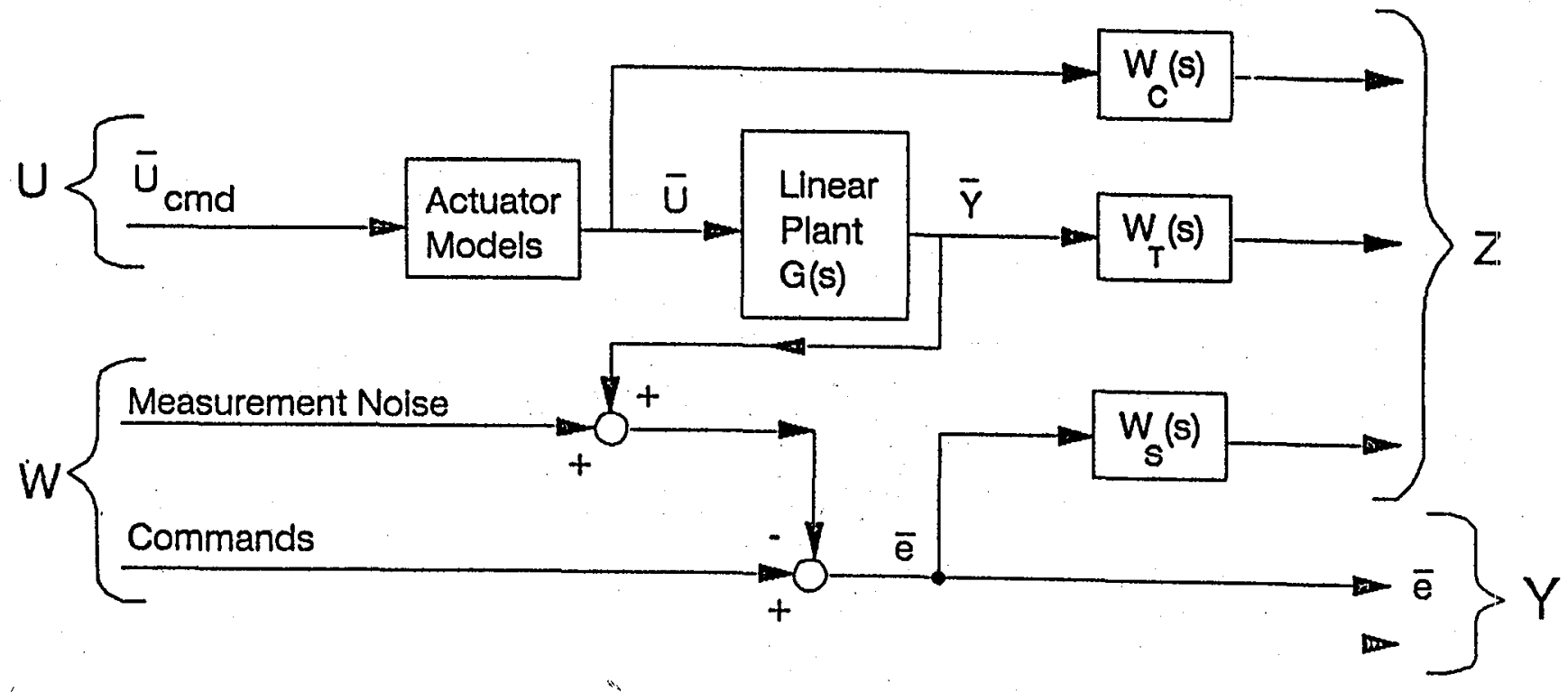

Figure $5 H_{\infty}$ Design Model Structure

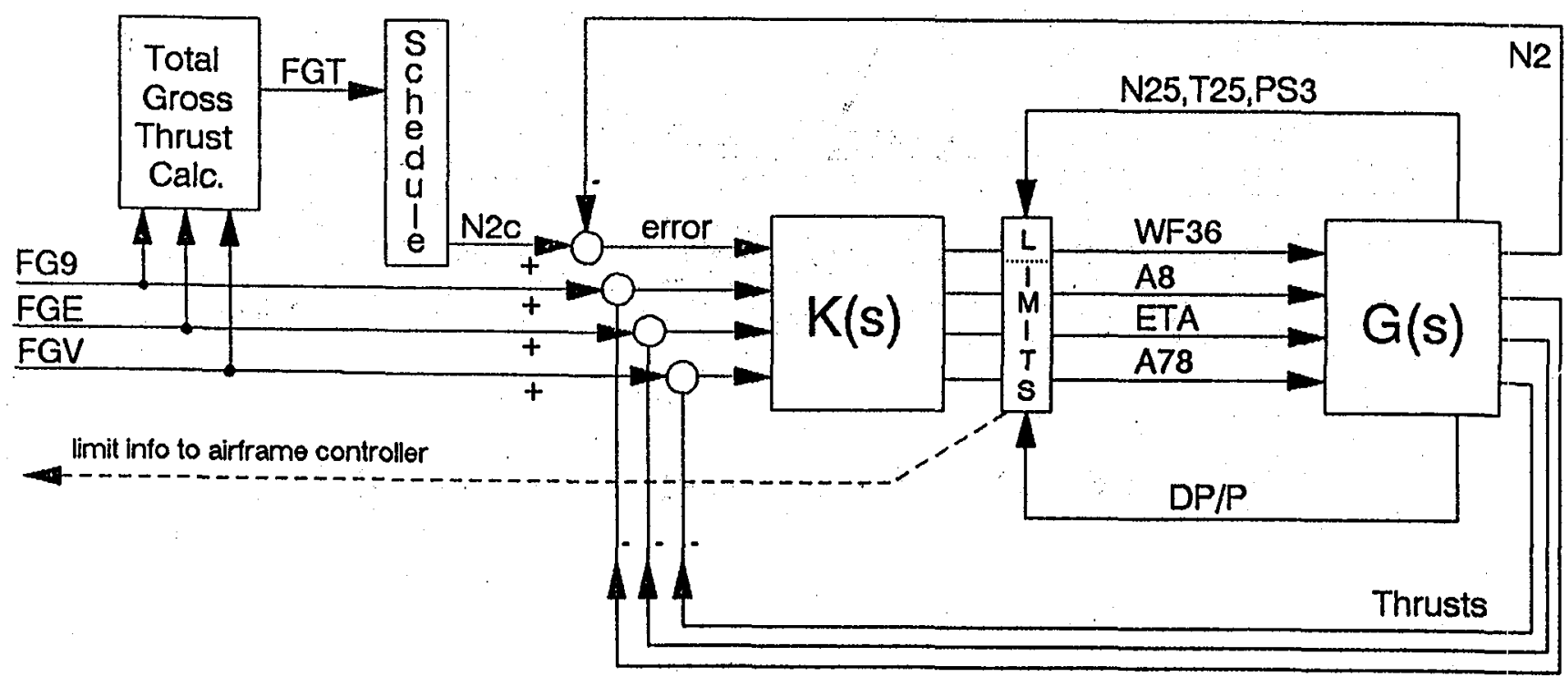

Figure 6 Implementation Structure for the N2 Loop Design 

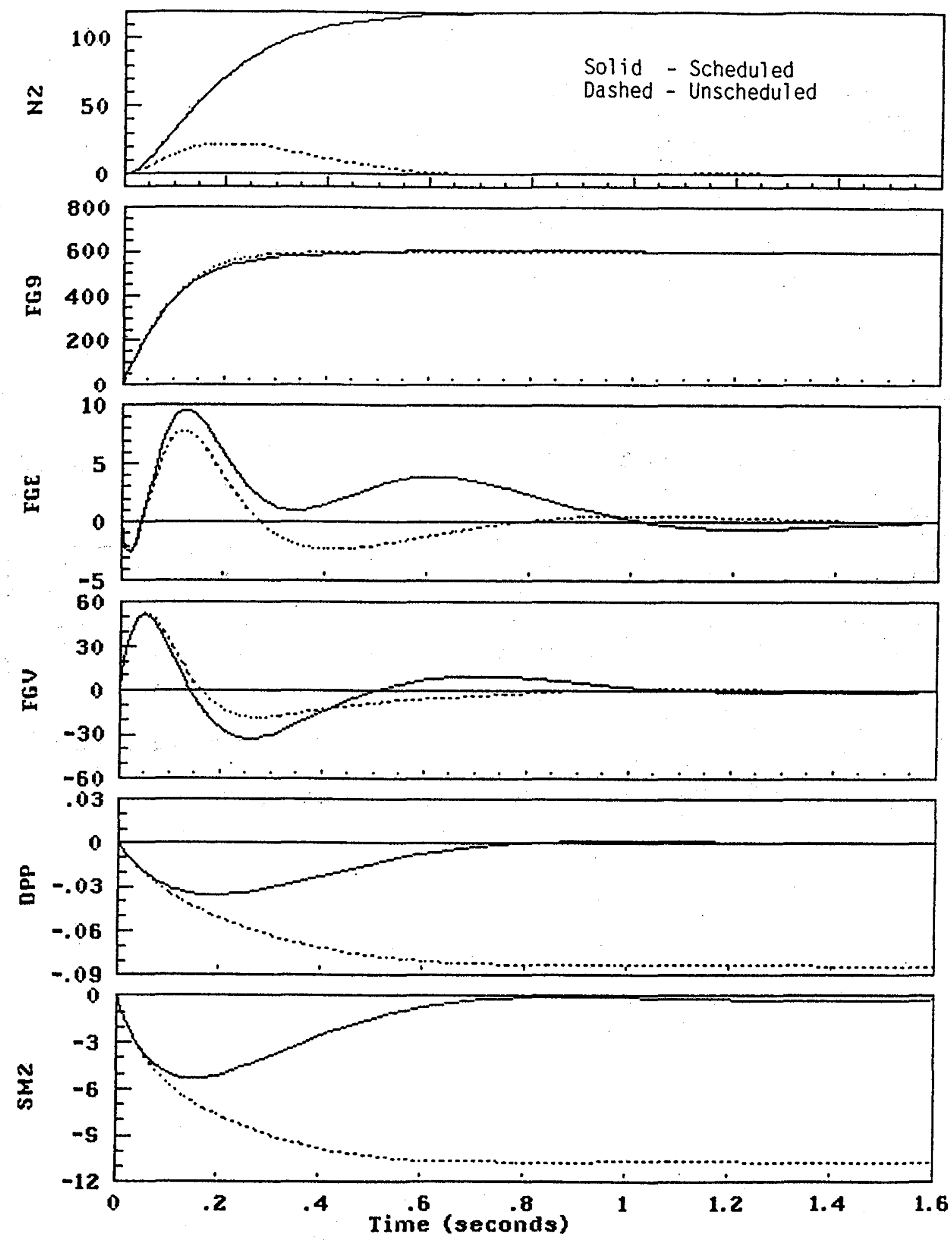

Figure 7 Comparison of N2 Loop Design with and without N2 Schedule to a $600 \mathrm{lbf}$ Step in FG9. 


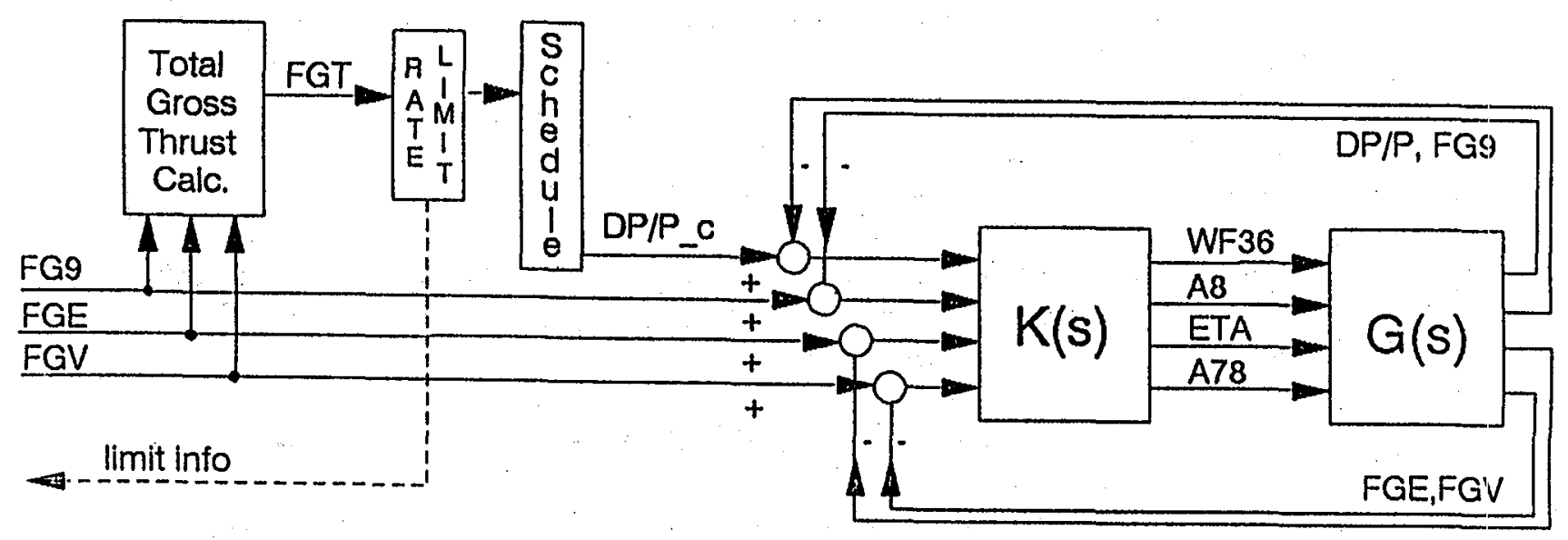

Figure 8 Implementation Structure for the DP/P Loop Design 

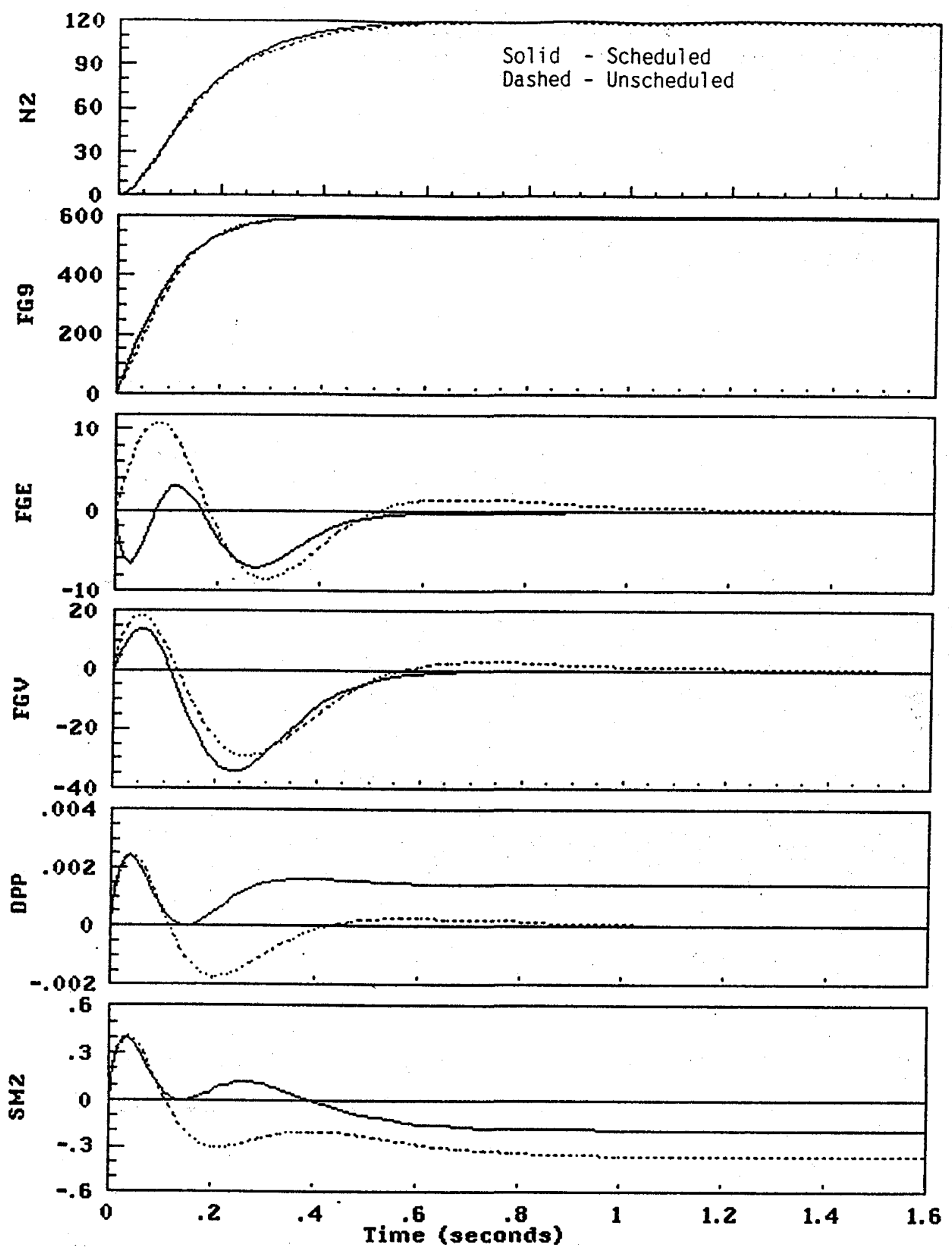

Figure 9 Comparison of DP/P Loop Design with and without DP/P Schedule to a $600 \mathrm{lbf}$ Step in FG9. 

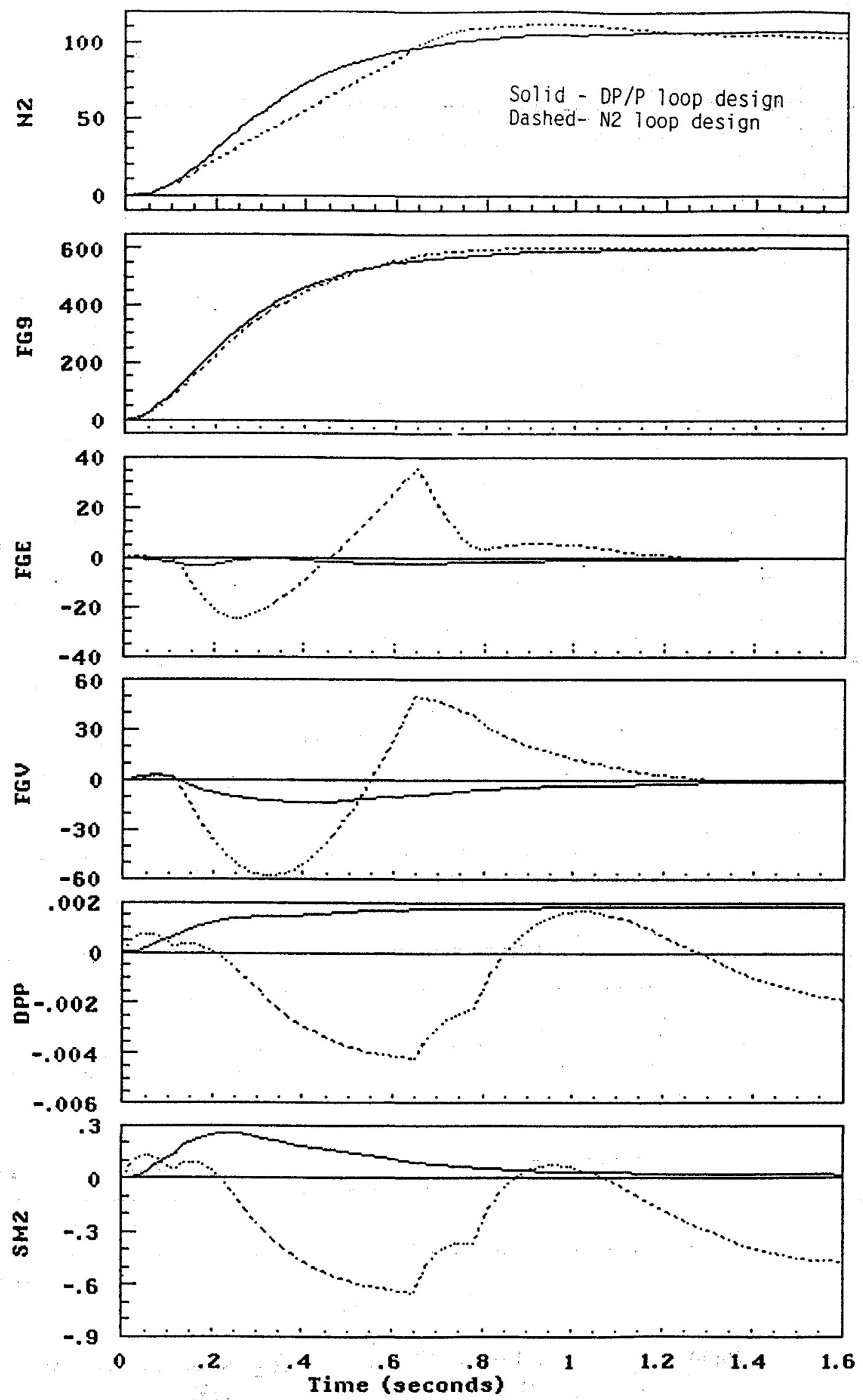

Figure 10 Comparison of DP/P Loop Design to the N2 Loop Designs with DP/P Limit Protection to a first order FG9 Command 
Public reporting burden for this collection of information is estimated to average 1 hour per response, including the time for reviewing instructions, searching existing data sources, gathering and maintaining the data needed, and completing and reviewing the collection of information. Send comments regarding this burden estimale or any other aspect of this collection of information, including suggestions for reducing this burden, to Washington Headquarters Services, Directorate for information Operations and Reports, 1215 Jeflerson Davis Highway, Suite 1204, Arlington, VA 22202-4302, and to the Office of Management and Budget, Paperwork Reduction Project (0704-0188), Washington, DC 20503.
1. AGENCY USE ONLY (Leave blank) 2. REPORT DATE
3. REPORT TYPE AND DATES COVERED
Technical Memorandum

4. TITLE AND SUBTITLE

A Linear Control Design Structure to Maintain Loop Properties During Limit Operation in a Multi-Nozzle Turbofan Engine

5. FUNDING NUMBERS

6. AUTHOR(S)

WU $505-62-50$

Duane Mattern and Peter Ouzts

7. PERFORMING ORgANIZATION NAME(S) AND ADDRESS(ES)

National Aeronautics and Space Administration

Lewis Research Center

Cleveland, Ohio $44135-3191$

8. PERFORMING ORGANIZATION REPORT NUMBER

$E-6452$

9. SPONSORING/MONITORING AGENCY NAMES(S) AND ADDRESS(ES)

National Aeronautics and Space Administration

Washington, D.C. 20546-0001

10. SPONSORING/MONITORING AGENCY REPORT NUMBER

NASA TM -105163

AIAA - 91-1997

\section{SUPPLEMENTARY NOTES}

Prepared for the 27th Joint Propulsion Conference cosponsored by the AIAA, SAE, ASME, and ASEE. Duane Mattern, Sverdrup Technology, Inc., Lewis Research Center Group, 2001 Aerospace Parkway, Brook Park, Ohio 44142 (work funded by NASA Contract NAS3 - 25266). Peter Ouzts, NASA Lewis Research Center.

12a. DISTRIBUTION/AVAILABILITY STATEMENT

12b. DISTRIBUTION CODE

Unclassified - Unlimited

Subject Categories 07 and 08

13. ABSTRACT (Maximum 200 words)

The implementation of multi-variable control systems on turbofan engines requires the use of limit protection to maintain safe engine operation. Since a turbofan engine typically encounters limits during transient operation, the use of a limit protection scheme that modifies the feedback loop may void the desired "guarantees" associated with linear multivariable control design methods, necessitating considerable simulation to validate the control with limit protection. An alternative control design structure is proposed that maintains the desired linear feedback properties when certain safety limits are encountered by moving the limit protection scheme outside of the feedback loop. This proposed structure is compared to a structure with a limit protection scheme that modifies the feedback loop properties. The two design structures are compared using both linear and nonlinear simulations. The evaluation emphasizes responses where the fan surge margin limit is encountered.

14. SUBJECT TERMS

Turbofan engines; Control systems design; Linear systems

15. NUMBER OF PAGES

28

16. PRICE CODE

$\mathrm{A} 03$

17. SECURITY CLASSIFICATION OF REPORT Unclassified

18. SECURITY CLASSIFICATION OF THIS PAGE Unclassified
19. SECURITY CLASSIFICATION OF ABSTRACT Unclassified 
11. Supplimentary Notes (continued)

Responsible person, Duane Mattern, (216) 433 - 8186. 
National Aeronautics and

Space Administration

Lewis Research Center

Cleveland, Ohio 44135

Otficial Business

Penalty for Private Use $\$ 300$

\section{FOURTH CLASS MAIL}

ADDRESS CORRECTION REQUESTED

\section{료}

Poslage and Fees Paid

National Aeronautics and

Space Administration

NASA 45 